\title{
O jogo do telegrama como material didático para a introdução da decomposição de um número em fatores primos
}

\author{
Gabriela dos Santos Barbosa \\ Professora, UERJ / FEBF
}

\section{Sandra Maria Pinto Magina}

Professora, UESC / PUC-SP

\section{Resumo}

Este texto relata um estudo cujo objetivo foi investigar, por meio da identificação e análise dos esquemas empregados por 22 estudantes do 60 ano do Ensino Fundamentalde uma escola particular do Rio de Janeiro, as contribuições de uma atividade lúdica - o jogo do telegrama - para a compreensão da decomposição de um número em fatores primos. Trata-se de um estudo analítico, desenvolvido a partir das ideias teóricas de Vergnaud. A análise permitiu reconhecer que a situação do jogo, bem como suas representações, favoreceram apropriações de esquemas referentes à decomposição de um número em fatores primos pelos alunos.

Palavras-chave: Jogo. Decomposição em fatores primos. Teoria dos Campos Conceituais. Ensino Fundamental. intervenção de ensino.

\section{The telegram game as a didactical material to introduce the decomposition of a number in prime factors}

\begin{abstract}
This paper reports a study whose objective was to investigate, through the identification and analysis of the schemes employed by 22 students in the 6th grade of elementary school from a private school sited in Rio de Janeiro, the contributions of a play activity - the game's telegram - to understand the decomposition of a number in prime factors. This is an analytical study, based on Vergnaud's theoretical ideas. The analysis allowed us to recognize that game situation, as well as its representations, may help students to appropriate some schemes related to the prime factors decomposition.
\end{abstract}

Keywords: Game. Prime factors decomposition. Theory of Conceptual Fields. Secondary School Students. teaching intervention. 


\section{Introdução}

Os conceitos utilizados na decomposição de um número em fatores primos pertencem à Teoria dos Números, que é abordada no âmbito da Aritmética. As pesquisas de Lins e Gimenez (1997), Campbell (2002), Coelho et al. (2003) e Barbosa (2008), indicam a existência de problemas no ensino e na aprendizagem da Aritmética. Lins e Gimenez (1997), por exemplo, afirmam que muitas possibilidades de abordagem dos conceitos relacionados à Aritmética são reduzidas ao ensino de algoritmos.

Nessa direção, Campbell (2002), Brown et al. (2002) e Teppo (2002) realizaram estudos focando na estrutura multiplicativa e na decomposição de números em fatores primos. Em linhas gerais, tais pesquisas estavam interessadas na compreensão que professores em formação tinham sobre a Teoria dos Números. Concluíram que,com frequência, eles lidavam com as tarefas dessa teoria sem a consciência dos conhecimentos multiplicativos subjacentes.

No Brasil destacamos os estudos de Coelho et al. $(2003,2005)$ de Resende (2007) e de Barbosa (2008), que investigaram o tema. Coelho et al. (2003) fizeram uma análise de propostas curriculares nacionais, identificando descontinuidades entre o ensino da aritmética na educação básica e nos cursos superiores de formação de professores. Eles apontam a necessidade do ensino da Teoria Elementar dos Números para esses últimos.

Em 2005, Coelho et al. investigaram a compreensão do Teorema Fundamental da Aritmética (TFA) por professores de Matemática em curso de formação continuada e por alunos da $8^{\text {a }}$ série (atualmente $9^{\circ}$ ano) do Ensino Fundamental de São Paulo. As pesquisadoras concluíram que a compreensão dos alunos era muito restrita, voltada basicamente para o algoritmo. Atentaram para o fato de que algumas concepções dos professores foram próximas das dos alunos, de modo geral estas eram mais amplas. As autoras reafirmaram a necessidade de uma abordagem com ênfase na formação de conceitos, evitando a memorização de algoritmos, desde os anos iniciais do Ensino Fundamental.

Já Resende (2007), analisou as propostas curriculares das disciplinas de 12 universidades brasileiras que tratavam da Teoria dos Números nos cursos de licenciatura em Matemática. Ela concluiu que: (a) essas instituições não se preocupavam com a parte prática da formação do professor da escola básica; (b) o ensino se enquadrava na tendência formalista clássica, com ênfase na abordagem axiomática, nas demonstrações, na divisibilidade e nas propriedades dos naturais e (c) havia premência de mudança curricular nos cursos de formação inicial.

Já Barbosa (2008), fundamentada nos estudos citados anteriormente, realizou uma intervenção de ensino com alunos do $6^{\circ}$ ano do Ensino Fundamental, focando a construção dos principais conceitos associados ao TFA. A autora confirmou a 
impossibilidade de um conceito ser compreendido de maneira isolada pelo aprendiz (VERGNAUD, 2009), identificando aqueles relacionados a decomposição de fatores primos: definições de múltiplos e fatores de um número, critérios de divisibilidade e diferenciação entre primos e compostos. Ela propõe ainda que, nas discussões que tratam de todos estes conceitos, alunos e professor se envolvam em um processo matemático de grande extensão que inclui organizar informações, fazer generalizações a partir de padrões numéricos, conjecturar e formar abstrações.

A seguir, passamos à descrição e análise qualitativa de nosso estudo intervencionista, que foi realizado sob a ótica da Teoria dos Campos Conceituais (TCC). Aqui abordaremos uma das atividades dessa intervenção, o jogo do telegrama. Visando o TFA, o jogo aconteceu após a realização de quatro outras atividades que enfocaram os conceitos de múltiplo, fator e suas propriedades e a noção de decomposição de um número. É importante esclarecer que os principais aspectos da TCC utilizados em nosso estudo serão apresentados e discutidos nas próximas seções, tendo como referência o desenvolvimento do jogo.

\section{O estudo}

A TCC, segundo Vergnaud (1990, 1994, 2009), afirma ser necessária a oferta de situações diversificadas para que o aluno identifique os invariantes de um determinado conceito. Além disso, um conceito não pode ser compreendido isoladamente porque está inserido em um campo conceitual e sua compreensão está associada à compreensão dos outros conceitos que compõem o campo. Tendo em vista o TFA e suas aplicações, é necessário que o aluno seja capaz de identificar se um número é, ou não, múltiplo/fator de outro, reconhecer as propriedades dessas relações, listar o conjunto dos múltiplos/fatores de um número, diferenciar números primos dos compostos, reconhecer propriedades dos números primos, decompor em fatores primos e operar com números representados na forma fatorada.

A partir dessa visão, realizamos um estudo com o objetivo de investigar, por meio da identificação e análise dos esquemas empregados por 22 estudantes do $6^{\circ}$ ano do Ensino Fundamental de uma escola particular do Rio de Janeiro, as contribuições de uma atividade lúdica - o jogo do telegrama - para a compreensão da decomposição de um número em fatores primos.

É importante esclarecer que a decomposição numérica faz parte do currículo escolar desde o $5^{\circ}$ ano do Ensino Fundamental, o que significa que esses alunos já tiveram contato com o conceito. Mas a nossa intenção foi retomar a decomposição com foco na introdução de conceitos associados ao TFA, utilizando uma intervenção de ensino com base em sete atividades lúdicas.Uma delas foi o jogo do telegrama, 
realizado em três aulas de 50 minutos cada, em uma única semana. Elas foram videografadas, de tal forma a assegurar que todos os participantes (alunos, pesquisadora e professora $^{1}$ ) fossem observados e ouvidos. Quando necessário, realizamos entrevistas informais, in loco, para esclarecer alguma conduta(oral, escrita ou gestual)assumida pelo estudante durante o jogo. Na análise de cunho qualitativo, identificamos nos esquemas, os teoremas em ação dos estudantes observados. No âmbito da TCC, Vergnaud $(1990 ; 157)$ define esquema como "a organização invariante do sujeito para uma classe de situações". Ainda segundo o pesquisador, fazendo parte dos esquemas estão os invariantes operatórios, que podem trazer tanto conhecimentos explícitos quanto implícitos e, ainda, podem ser verdadeiros ou falsos. Quando estão implícitos, esses conhecimentos são chamados de teoremas em ação. Por fim, Vergnaud explica que os invariantes operatórios referem-se tanto às propriedades dos objetos matemáticos quanto aos procedimentos utilizados pelos sujeitos em suas interações com tais objetos.

\section{O JOGO DO TELEGRAMA}

Organização da classe: Os 22 alunos se organizaram em quatro grupos, três grupos com seis e um grupo de quatro componentes.

Material didático: 10 folhas em branco de papel A4 para cada grupo.

Regra do jogo: Uma folha dividida em várias partes deve circular entre os alunos de um mesmo grupo. Na primeira parte é colocado um número ditado pela pesquisadora. O primeiro aluno do grupo escreve uma decomposição qualquer do número ditado e passa o papel para o segundo membro do grupo. Este não consegue ver a decomposição do colega, escreve a sua decomposição para o mesmo número, dobra o papel encobrindo as duas decomposições e passa o papel para o próximo colega, e assim por diante até que todos tenham escrito uma decomposição possível para o número ditado pela professora. Ganha o jogo a equipe que produzir a maior quantidade de decomposições diferentes para o mesmo número.

Procedimento: Inicialmente o jogo foi realizado de maneira livre. Entretanto, para que se alcançassem os objetivos, após algumas partidas a professora passou a ditar condições para as decomposições. Por exemplo, na primeira etapa, a professora dizia "usando apenas soma", na segunda, "usando apenas

1. A professora participou de todos os encontros com duas funções: (a) minimizar o efeito da pesquisadora na sala, já que a cobrança de condutas de comportamento era feita pela professora e (b) servir de auxiliar de pesquisa, circulando entre os grupos, observando suas ações e tirando dúvidas relacionadas às regras do jogo. Após cada encontro, pesquisadora e professora se reuniam para avaliá-lo. 
a multiplicação de dois números" e, na terceira, "usando a multiplicação de três números". Havia a preocupação por parte da pesquisadora em escolher um repertório variado de números para serem usados em cada partida. Os grupos trabalharam com números pequenos (menores que 50), grandes (maiores que 50), pares, ímpares, primos, compostos (não primos) e quadrados perfeitos.

\section{Análise do jogo do telegrama}

Em princípio não nos preocupamos com as operações que os alunos teriam/deveriam/ poderiam usar para decompor o número dado. Ditávamos apenas os números e os alunos eram livres para usar a operação que desejassem em suas escritas. Nessas condições, quase todas as escritas produzidas envolviam apenas adições e subtrações, como mostramos na Figura 1.

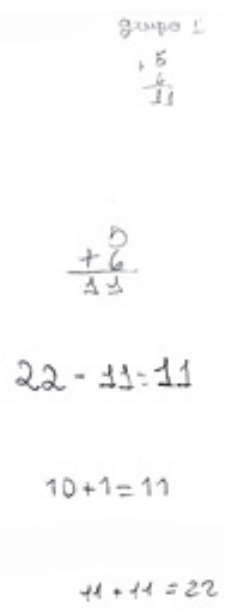

Figura 1: Ficha do jogo do telegrama contendo apenas adições e subtrações.

Como mostra a Figura 1, a ação do grupo foi usar as operações de adição e subtração para decompor o número 11 ditado por nós. Os outros dois grupos produziram fichas muito semelhantes a essa e apenas um grupo realizou uma multiplicação, além das adições e subtrações. Um dos integrantes desse último grupo escreveu uma multiplicação $11 \times 1=11$. A nossa primeira interpretação para a pequena incidência de multiplicações foi de que tal fato aconteceu pela presença do número 11, que é primo. Entretanto, quando ditamos os números compostos 12 e 18, os esquemas dos alunos não diferiram muito dos apresentados na Figura 1. 
Nas entrevistas informais, 15 alunos afirmaram achar muito difícil descobrir divisões que resultassem nos números que ditávamos. Faziam comentários como: "tem que ficar testando muito e, às vezes, não dá em nada." Apenas um aluno comentou que "tem que ficar fazendo contas de multiplicar, não dá para fazer de cabeça".

Os comentários sugeriram-nos que, embora não verbalizasse, este último aluno reconhecia no jogo uma situação em que podia aplicar seus conhecimentos sobre as igualdades matemáticas, o que foi confirmado quando lhe pedimos que explicasse melhor seu pensamento: "se eu quero chegar no 18, eu faço 18 vezes 2 e vejo quanto vai dar; ai eu escrevo o número dividido por 2, mas é muito chato, tem que fazer conta armada."

Reconhecemos como implícito nas ações descritas pelo aluno o conhecimento da reversibilidade entre multiplicação e divisão, o que nos permite classificá-lo como um teorema em ação (VERGNAUD, 1994). É importante destacar que os algoritmos da multiplicação e da divisão, que também estão implícitos na ação do estudante, fazem parte do campo conceitual multiplicativo, assim como a proporção, a fração, a função linear e a própria decomposição em fatores primos, entre muitos outros conceitos.

Quando passamos a ditar o número e a operação que deveriam constar nas fichas, identificamos outro tipo de problema: em um mesmo grupo, sem terem acesso à escrita que os companheiros de grupo já haviam produzido, os alunos produziram decomposições idênticas. Na Figura 2 oferecemos um exemplo de uma ficha.

Registro da decomposição feita pelo primeiro aluno do grupo.

Sem ter acesso ao registro do primeiro aluno, $5 \times 6=3 c \quad$ o segundo faz o registro de sua decomposição.

$5 \times 6=30 \quad$ O registro do terceiro aluno.

$10 \times 3=30 \quad$ Assim se sucedem os registros...

$3 \times 10=30$

$6 \times 5=30$

Figura 2: Exemplo de uma ficha do jogo do telegrama de um dos grupos, com os produtos repetidos. 
Para a produção da ficha anterior, ditamos "30 e multiplicação", ou seja, os alunos deveriam escrever multiplicações cujo produto resultasse no número 30 . Assim, dos seis alunos que compunham o grupo, dois alunos escreveram $6 \times 5$, outros dois registraram $5 \times 6$. As respostas $10 \times 3$ e $3 \times 10$ foram de dois outros alunos. Convém destacar que as multiplicações $2 \times 15=30$ e $30 \times 1=30$ não foram escritas.

Inferimos que tal ausência ocorreu porque os alunos buscavam as multiplicações que constam nas tabuadas de 1 a 10. A incidência de casos análogos em todos os outros grupos reafirmou nossa inferência.

Em uma segunda etapa, estabelecemos as novas regras do jogo: (i) os grupos deveriam se sentar em roda; (ii) continuaríamos ditando números e operações; (iii) marcaríamos um tempo no relógio e o grupo que produzisse o maior número de escritas naquele intervalo seria vencedor.

Ao pedirmos que escrevessem multiplicações, as primeiras escritas eram obtidas pelo esquema descrito anteriormente, isto é, buscá-las nas tabuadas de 1 a 10. Entretanto, quando estas se esgotavam, identificamos dois esquemas distintos entre os alunos para obter mais decomposições. O primeiro, empregado inicialmente por 16 alunos, consistia em estimar aleatoriamente os pares de números que multiplicados resultariam nos números que ditávamos. Os alunos estimavam os pares e efetuavam os cálculos para validar ou invalidar suas estimativas. Já o segundo esquema, era o que se fundamentava na reversibilidade entre multiplicação e divisão. Ao empregar critérios de divisibilidade, os alunos encontravam um dos fatores do número ditado, realizavam a divisão deste último pelo primeiro para obter o quociente, que é o outro fator e, finalmente, ao descobrir tais fatores, eles escreviam as multiplicações.

É fundamental esclarecer que existem conhecimentos matemáticos implícitos em ambos os esquemas. No caso do primeiro esquema - estimativa - cujo emprego é mais demorado, para usá-lo os alunos precisavam de dois teoremas em ação: (a) reconhecer que os pares deviam ser formados por números menores que o número ditado e (b) que quanto maior fossem eles, maior seria o produto deles, ou seja, eles sabiam que, se os fatores fossem aumentados, o produto também ficaria maior. Considerando que nenhum aluno apresentou fator maior do que o número ditado, partimos da hipótesedeque eles reconheciam que os fatores de um número sempre são menores ou iguais a ele. Estas são propriedades verdadeiras para o produto de números naturais e a última corresponde ao seguinte teorema matemático: sejam $a$ e $b$ dois números inteiros, se $a$ divide $b$ e $a \neq b$, então $|a|<|b|$.

É importante salientar que, ao usar os teoremas em ação, os alunos precisavam ter se apropriado, mesmo que de maneira implícita, dos seguintes conceitos: as noções de cardinalidade, de múltiplo e fator, de multiplicação e divisão. 
Com relação ao segundo esquema, que se fundamenta na reversibilidade entre multiplicação e divisão, começamos por comentar o emprego dos critérios de divisibilidade. Embora não os expressassem em linguagem matemática formal, os alunos empregavam de maneira adequada os critérios de divisibilidade por 2, por 5 e por 10. Os erros aconteciam quando eles estendiam esses critérios de divisibilidade para outros números, como por exemplo, os números 3 e 4 . Atribuímos este fato à falta de compreensão e de reconhecimento por parte dos alunos do domínio de validade de seus esquemas.

Notamos,na extensão de um critério de divisibilidade, o uso de um falso teorema em ação, que é determinar o múltiplo de um número maior que 10verificando apenasse o último algarismo do maior número era ou não múltiplo do número menor. Por exemplo, o aluno decidia que 49 era múltiplo de 3 apenas porque o 9 era múltiplo do 3.Esse era um bom esquema para os números 2,5 e 10, mas não valia para os demais números. Segundo a TCC, temos outro teorema em ação, mas desta vez falso.

Para corrigir este falso teorema em ação, lançamos mão de inúmeros contraexemplos e favorecemos uma reflexão coletiva que possibilitou a sua interrupção, já que os alunos reconheceram que não era possível lançar mão dos mesmos critérios usados em 2, 5 e 10 para outros números. O sucesso das reflexões, comprovado pelo abandono de tal esquema em 16 dos 18 alunos que empregavam o falso teorema em ação, destaca a importância dos contraexemplos no processo de construção de conceitos.

Prosseguimos com o jogo e em determinado momento passamos a solicitar que os alunos usassem mais de uma operação para decompor os números que ditávamos. Por fim, pedimos que eles usassem duas, três ou quantas multiplicações quisessem em suas decomposições, mas os alunos continuaram se restringindo ao uso da multiplicação de dois fatores.

Parece que eles não compreendiam como fazer para obter três ou mais números que, multiplicados, resultaria no número ditado. Os esquemas que empregavam até então não permitiam obter um número de fatores maior que dois. Era preciso incorporar novas ações para transformar seus esquemas em outros mais abrangentes. Sozinhos, no tempo determinado para isso, não realizaram. Transcrevemos a seguir um diálogo sobre o desafio de escrever o número 60 como multiplicação de três fatores, para mostrar as reflexões dos alunos nesse sentido. Identificamos a pesquisadora pela letra P. As demais letras correspondem às iniciais dos nomes de cada aluno.

J: Sessenta é três vezes vinte.

M: Eu achei seis vezes dez.

P: Mas tem três números?

Coro: Não. 


\section{P: O que foi pedido?}

Coro: Multiplicação com três números.

P: Alguma ideia?

J: Posso fazer vinte mais vinte mais vinte?

P: É multiplicação?

M: Não. Não pode, não! Você tá falando mais.

Notamos que a aluna $\mathbf{J}$, assim como 13 dos 22 alunos, recorreu à decomposição em três parcelas e não em três fatores. Este fato, associado ao material produzido pelos alunos nas primeiras rodadas,nas quais eram livres para escolherem as operações que desejassem, confirma a tendência verificada por Campbell (2002), de os alunos pensarem aditivamente.

A ação da aluna $\mathbf{J}$ também revela a ideia defendida há anos por Vergnaud (1990), deque no confronto do indivíduo com uma situação para a qual ele não possui esquemas suficientes, ele emprega os esquemas válidos para outras situações que possuem aspectos semelhantes à situação dada.

No caso dos alunos de nosso estudo, as novas ações incorporadas ao esquema antigo buscando dar conta da nova situação seriam: (a) decompor em fatores um dos dois fatores da primeira decomposição e (b) substituí-lo por tal decomposição (por exemplo, no caso do número 60 , a primeira decomposição seria $6 \times 10$ e a partir daí o aluno substituiria 10 por $2 \times 5$ e, então, registraria " $6 \times 2 \times 5$ "). Entretanto, os alunos só passaram a empregar tais esquemas depois de nossa intervenção.

Nossa participação foi inicialmente muito incisiva e pouco esclarecedora. Pedimos no exemplo do número 60, com a primeira decomposição $6 \times 10$ (que todos fizeram sem problema) que decompusessem tanto o número 10 como o número 6 . Os alunos ficaram muito confusos, sem entender a solicitação e perseguindo vários caminhos sem avanços na decomposição inicial. Diante da constatação de que nosso pedido havia causado uma desordem cognitiva nos alunos, refletimos novamente e escolhemos outra fatoração do número 60 .Optamos por $3 \times 20$ justamente porque o 3 era um número primo e, portanto, os alunos teriam que fazer a próxima fatoração apenas no número 20. A nova abordagem parece ter facilitado porque a partir de então os alunos deram os primeiros passos na compreensão da decomposição em mais de dois fatores, chegando a respostas do tipo: " $3 \times 2 \times 10$ " ou " $3 \times 10 \times 2$."

Durante o jogo, propusemos que os alunos escrevessem o número 12 como um produto de primos e tivemos a oportunidade de avançar nas discussões iniciadas anteriormente. No caminho encontramos, pelo menos, dois aspectos que merecem comentários. O primeiro se refere ao pensamento aditivo, expresso na fala da aluna $\mathbf{J}$ descrita anteriormente. Notamos que, mais uma vez, diante de um problema 
multiplicativo, nove alunos insistiram em pensar aditivamente, tal como constatado nas pesquisas de Campbell e Zazquis (2002).

O segundo aspecto se refere à possibilidade de escrevermos fatores repetidos. Esta ideia, assim como a de substituir um número pela sua decomposição, não foi facilmente aderida pelos alunos. Foi preciso que insistíssemos em propostas como a de decompor em primos para que ela viesse à tona. Vale destacar que, ao se trabalhar com números maiores, a decomposição em números primos requer que o aluno repita de modo recursivo a ação de substituir cada fator por sua decomposição em outros fatores até que todos os fatores sejam primos. A ideia de, a priori, repetir uma ação indefinidas vezes não foi facilmente assimilada por eles e julgamos que nossa intervenção foi necessária.

Complementando o jogo, solicitamos a todos os alunos que fizessem, individualmente e por escrito, a decomposição dos números 90, 64, 144 e 945 em fatores primos. Encontramos erros e acertos. O erro mais comum foi o de fazer a decomposição incompleta, não realizando novas fatorações, até encontrar todos os fatores primos do número dado. A Figura 3 apresenta uma ficha com tal situação.

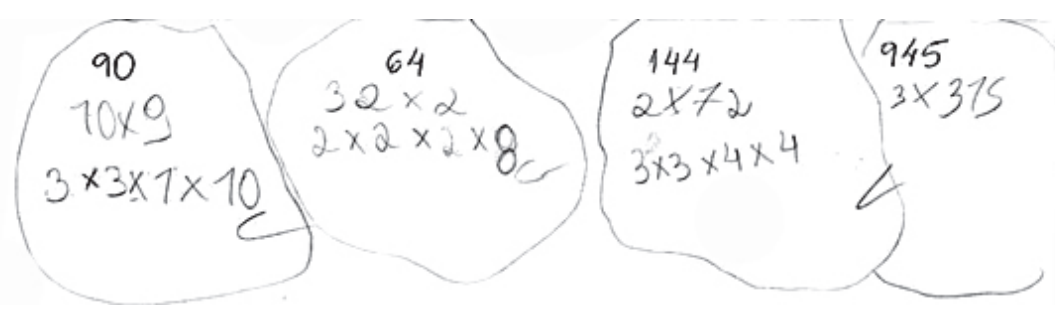

Figura 3: Decomposição envolvendo fatores primos e compostos dos números 90, 64, 144 e 945.

Como mostra a Figura 3, o aluno inicia o processo de decomposição em fatores, realiza substituições obtendo alguns fatores primos, mas interrompe o processo antes de encontrar todos os fatores primos. Por exemplo, na decomposição do número 90 o número 10 ainda deveria ser substituído por $2 \times 5$. Isto evidencia para nós que o aluno empregou o esquema, mas não teve o controle das circunstâncias, no exemplo, a falta de cumprimento de todas as etapas nas quais ele devia ser empregado. Fica claro que ele não possuía ainda um critério claro para decidir quando devia prosseguir com as ações de substituição ou interrompê-la. Este controle integra a conceptualização em questão (Vergnaud, 1990). O aluno ainda não tem o controle das circunstâncias nas quais seus esquemas devem ser empregados. Neste caso, o processo de conceptualização ainda não está completo. 
Outro aspecto que também verificamos nas ações dos alunos foi o "esquecimento" de alguns fatores primos que já haviam sido identificados no processo de decomposição. A Figura 4 ilustra essa ação.
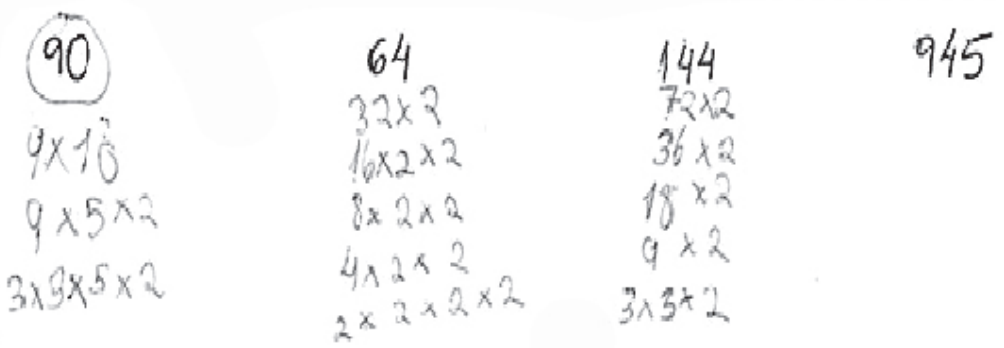

Figura 4: Esquecimento de alguns fatores primos durante a decomposição.

Notemos que, com o número 90 o aluno realizou adequadamente a decomposição. Já com os números em que as quantidades de fatores primos eram maiores, precisando repetir mais vezes a ação de substituição de um fator pela sua decomposição em fatores, o aluno se atrapalhou. Por exemplo, na decomposição do número 64, e mais ainda na decomposição que apresentou para o número 144, na qual o aluno substituiu um fator pela sua decomposição, mas não repetiu o outro fator usado na decomposição anterior.

Observamos que, de modo diferente ao do aluno cujo registro foi comentado na Figura 3, esse aluno sabia o momento de interromper o processo, pois, em todos os itens, chegou a fatores primos. Tal fato nos sugeriu que esse erro talvez fosse decorrente do uso inadequado da linguagem matemática, do desconhecimento das propriedades que asseguram a igualdade entre duas expressões matemáticas e do desconhecimento sobre como devem ser representadas.

Ficou evidente para nós, a partir dos registros da Figura 4, que o aluno ainda não dominava as representações associadas ao conceito. Vergnaud (1990) enfatiza que o uso adequado da simbologia associada ao conceito é um dos elementos que o compõe Portanto, também inferimos que os alunos que cometiam esse erro ainda não dominavam plenamente a decomposição em fatores primos.

Ainda sobre a ação do aluno presente na Figura 4, notamos que ele nem ao menos tentou a decomposição do número $945 \mathrm{em}$ fatores primos. Tivemos 15 alunos que deixaram em branco ou erraram na decomposição desse número. Entrevistamos, informalmente 13 deles e constatamos que o fato de 945 ser um número ímpar e, ainda, muito maior do que 90, 64 e 144 tornou-se um obstáculo. Os alunos não 
conseguiam encontrar sua decomposição em dois fatores, que deveria ser o ponto de partida para as substituições. Diante desta dificuldade, ou não faziam ou pensavam aditivamente, conforme mostra a Figura 5.

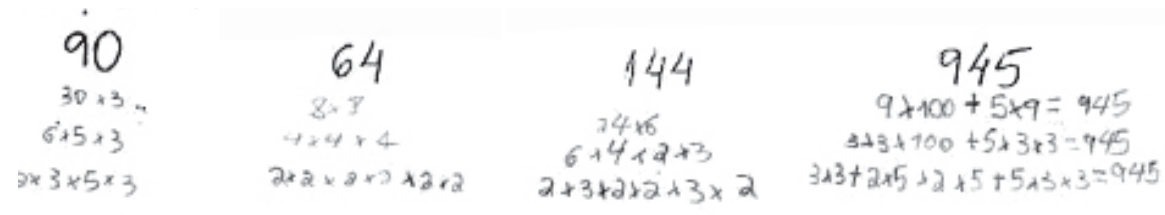

Figura 5: Pensamento aditivo na decomposição em fatores primos do número 945.

Observamos que o aluno acertou a decomposição em fatores primos dos números 90, 64 e 144, mas iniciou a decomposição de 945 repartindo-o em $900+$ 45. A partir daí, fez as decomposições de cada uma das parcelas.

Por fim, vamos comentar os acertos. Dos 22 alunos, apenas seis acertaram a decomposição em fatores primos de todos os números solicitados. Na Figura 6, ilustramos um exemplo de um desses seis alunos.

\begin{tabular}{|c|c|c|c|}
\hline 90 & 64 & 144 & 945 \\
\hline $\begin{array}{l}9 \times 10 \\
3 \times 3 \times 10 \\
3 \times 3 \times 2 \times 5\end{array}$ & $\begin{array}{c}32 \times 2 \\
16 \times 2 \times 2 \\
8 \times 8 \times 2 \times 2 \\
4 \times 4 \times 2 \times 2 \\
2 \times 2 \times 2 \times 2 \times 2 \times 2\end{array}$ & \begin{tabular}{|}
$72 \times 2$ \\
$12 \times 6 \times 2$ \\
$4 \times 3 \times 6 \times 2$ \\
$2 \times 2 \times 3 \times 2 \times 3 \times$ \\
$2^{2}$
\end{tabular} & $\begin{array}{l}189 \times 5 \\
63 \times 3 \times 5 \\
21 \times 3 \times 3 \times 5 \\
7 \times 3 \times 3 \times 3 \times 5\end{array}$ \\
\hline
\end{tabular}

Figura 6: $O$ aluno acertou a decomposição em fatores primos de todos os números.

Os alunos entregaram também suas folhas de rascunho e, pelos cálculos escritos nelas, verificamos que, para identificar os produtos, ora eles efetuavam as divisões, ora faziam estimativas mentalmente. Na segunda ação, efetuavam os cálculos para comprovar sua estimativa. Na Figura 7, além de apresentar outro caso de acerto, trazemos o registro de uma aluna que verificou que a decomposição do número em fatores era igual ao próprio número. 


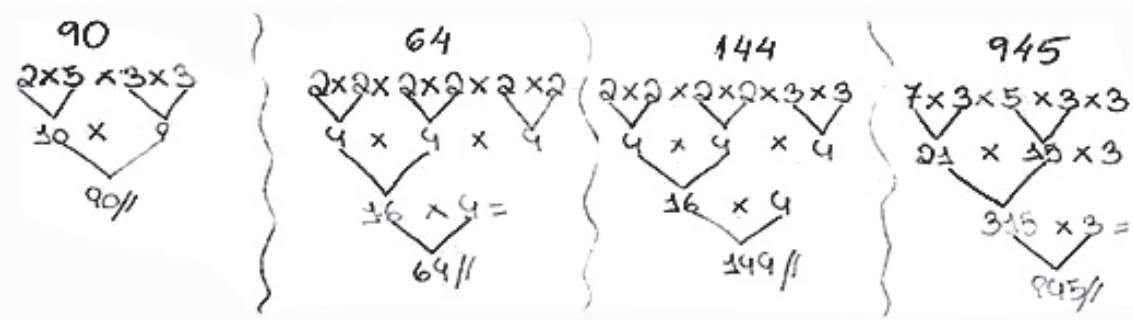

Figura 7: Decomposição em fatores primos com prova real.

Após decompor os números em fatores primos, a aluna refez as multiplicações e verificou seus resultados em uma espécie de prova real.2

\section{Considerações Finais}

Neste artigo investigamos as contribuições de uma atividade lúdica para a compreensão da decomposição de um número em fatores primos. Para tanto, analisamos as condutas de 22 alunos de $6^{\circ}$ ano ao participarem do jogo do telegrama, à luz da TCC. Identificamos e analisamos os esquemas empregados por esses alunos enquanto jogavam e os teoremas em ação que compunham tais esquemas. Em todas as etapas observamos que o jogo parece ter criado condições para que a maioria dos alunos desenvolvesse e utilizasse diversas representações para lidar com os conceitos, além de ser, em si, uma situação em que eles puderam construir os conceitos de forma significativa. Uma vez que a atividade foi realizada em grupo, observamos que foi proveitosa a troca de informações entre os alunos, o que pode ter contribuído para o aprendizado individual. A articulação entre as várias formas de representação foi feita de tal modo que parece ter permitido que alunos adquirissem confiança para expressar seus esquemas, tornando a aprendizagem mais eficiente.

$\mathrm{Na}$ ação dos alunos, identificamos uma série de teoremas matemáticos implícitos, nomeados por Vergnaud como teoremas em ação. Lembramos que eles fazem parte dos invariantes operatórios e esses são elementos constitutivos do esquema. Procuramos organizá-los e constatamos, mais uma vez, que os fenômenos relacionados à construção de conceitos não se dão de forma linear. Não se trata de estabelecer relações estritas de causa e efeito. Muitos fatores conjugam-se e interagem durante a construção de conceitos, proporcionando avanços e retrocessos.

2. Na decomposição do número 144 , pareceque a aluna escreveu 3 ' $3=4$. Prosseguindo, notamos que se tratava do número 9 , pois na linha seguinte ela multiplicou 16 por 9 e apresentou como resultado 144 . Supomos que o que parecia o 4 era o numeral 9 mal desenhado. 
Por fim, o jogo do telegrama foi um entre sete atividades lúdicas desenvolvidas ao longo da intervenção de ensino com esses alunos e a cada nova atividade realizada por eles ficava evidente a apropriação dos conceitos envolvidos no TFA.

\section{Referências}

BARBOSA, Gabriela S. O Teorema Fundamental da Aritmética: jogos e problemas com alunos do sexto ano do Ensino Fundamental.Tese de doutorado em Educação Matemática. São Paulo:Pontifícia Universidade Católica de São Paulo, 2008.

BROWN, Anne; THOMAS, Karen; TOLIAS, Georgia. Conceptions of divisibility: success and understanding. In: CAMPBELL, S.;Zazkiz, R. (Orgs.). Learning and Teaching Number Theory. Westport: Ablex Publishing, pp. 41-82, 2002.

CAMPBELL, Stephen R. Coming to terms with division: Preservice teachers' understanding. In: CAMPBELL, S.; Zazkiz, R. (Orgs.). Learning and Teaching Number Theory. Westport: Ablex Publishing, pp.1-14, 2002.

COELHO, Sônia; MACHADO, Sílvia; MARANHÃO, Cristina. Projeto: qual a álgebra a ser ensinada em cursos de formação de professores de matemática? Santos: SIPEM, 2003.

.Como é utilizado o Teorema Fundamental da Aritmética por atores do Ensino Fundamental? Porto: CIBEM V, 2005.

LINS, Romulo C.; GIMENEZ, Joaquim. Perspectivas em aritmética e álgebra para o século XXI. Campinas: Papirus, 1997.

RESENDE, Marilene R. Re-significando a disciplina Teoria dos Números na formação dos professores de matemática na licenciatura. Tese de doutorado em Educação Matemática. São Paulo:Pontifícia Universidade Católica de São Paulo, 2007.

TEPPO, Anne R. Integrating content in classroom Mathematics. In: CAMPBELL, S.;Zazkiz, Rina. (Orgs.).Learning and Teaching Number Theory. Westport: Ablex Publishing, pp.117-130, 2002.

VERGNAUD, Gerard. La théorie des champs conceptuels. Recherches en Didactique des Mathématiques, v. 10, n. 23, pp. 133-170, 1990. 
. Multiplicative conceptual field: what and why? In Guershon, H.; Confrey, J. (Eds.) The development of multiplicative reasoning in the learning of mathematics. Albany, N.Y.: State University of New York Press. pp. 41-59, 1994. A criança, a matemática e a realidade. Trad. Mara Lúcia Moro. Curitiba:Ed. UFPR, 2009.

Submetido em junho de 2012 Aprovado em novembro de 2012 